\title{
Low-Tech Sector Performance in Lithuania
}

\author{
Jurate Pridotkiene, Assoc.Prof. Dr.
}

Department of Economics and International Trade Kaunas University of Technology, Lithuania Email: jurate.pridotkiene@ktu.It

Daiva Laskiene, Assoc.Prof. Dr.

Department of Economics and International Trade Kaunas University of Technology, Lithuania Email: daiva.laskiene@ktu.It

Vitalija Venckuviene, Dr.

Department of Economics and International Trade Kaunas University of Technology, Lithuania Email: vitalija.venckuviene@ktu.It

\section{Doi:10.5901/mjss.2013.v4n11p265}

\section{Abstract}

OECD industry classification distinguishes four industrial groups in the manufacturing industry: high-tech, medium high-tech, medium low-tech and low-tech. Low-tech industries are deemed to be those that add little value to a country's economy and are less competitive, though recent studies in different countries show that they may be innovative and knowledge intensive ones. In the paper we aim to show what role low-tech industries play in Lithuanian manufacturing industry and the economy. Therefore the main aim of the paper is to make a comparative analysis of Lithuanian industries' data and reveal low-tech's contribution to Lithuanian manufacturing sector and the economy. For the analysis we use data from the Lithuanian Department of Statistics (Statistics Lithuania) and other data bases for the year 2010-2011. We base the comparative data analysis of different industrial sectors mainly on the set of indicators proposed by Laestadius, Pedersen \& Sandven (2006) and use additional one of orientation to export. The analysis showed that low-tech industries make a considerable contribution to Lithuanian manufacturing industry sector and is important to the whole economy, as well.

Keywords: technological level, industry classification, low-tech, industry indicators.

\section{Introduction}

In 2010 EU adopted a new strategy Europe 2020 to reach sustainable economic growth and especially growth in job places in order to cope with impact of the most severe economic crisis since 1930's. The objective of Europe 2020 is to develop smart growth through education, knowledge and innovation, sustainable growth through a resource-efficient, greener and more competitive economy and inclusive growth through high employment and economic, social and territorial cohesion (European Commission, 2010).

When talking about one of the key targets of the strategy - research and innovation - EU has ambition to reach 3 per cent of the EU's GDP invested into research and development. In fact the same target was set in the previous EU strategy, but it is still of interest to reach. For Lithuania this dimension is set at 1.9 per cent of GDP. For Lithuania to reach this ratio much of effort is needed. For comparison, annual R\&D growth was 4.1 per cent in the period or 20002011 and to reach the targeted 1.9 per cent, annual growth of 8.4 per cent is required until 2020, therefore policy makers have to search for every possibility to stimulate business and science to reach such growth.

High R\&D expenditures in a country are usually related to the intensive involvement of high-tech industries which are seen as being high-R\&D investing sector. However, studies in other countries show, that not only high-tech sector but also low-medium and even low-tech industries demonstrate innovativeness and knowledge creation facilities (HirschKreinsen, 2005). 
Another very important target issue addressed in the EU strategy is the increase of employment rates. European economy is still plagued by high unemployment rates, no exception is Lithuania. As Eurostat (2013) data shows, both in EA-17 and EU-27 unemployment is still increasing since 2011; at the end of 2012 unemployment reached as high as almost 26 million, what makes a record rate of 10.7 per cent in EU. In Lithuania situation is even worse, and though unemployment level decreased from 15.6 per cent in January 2012 to 14.9 in January 2013, the percentage is still very high. Especially bad situation is among young and unskilled labour force unemployment. Again, it was showed that lowtech industries may be a sector where a quite considerable part of labour force may be employed (Laestadius, Pedersen, \& Sandven, 2005). Therefore it is of great interest to explore if low-tech sector is capable to diminish the problem of unemployment, especially in problematic segments in Lithuania.

Considering the above addressed issues questions for the research in low-tech area arise: What is the role of lowtech sector in Lithuanian economy? Is it important, especially in the light of Europe 2020 strategy target achievement? May it help to reach targeted R\&D to GDP ratio, or is the sector desperate and shouldn't attract additional attention of innovation policy makers? If low-tech sector is not so much innovative, is it still important as a sector for employment? To answer these questions, the aim of the paper is stated as to make a comparative analysis of Lithuanian industries' data and reveal low-tech's contribution to Lithuanian manufacturing sector and the economy.

\section{Theoretical background}

For several decades economists and policy makers concentrated their effort on high-tech industries, hoping this sector will become the main driver of economies and growth. There's no doubt about high-tech input in creating high added value products and making intensive investment in R\&D. However, Eurostat (2013) data shows that high-tech sector created a little above 2 per cent of total value added in EU-27 economy.

There were several earlier attempts to define and distinguish the high-tech sector and create multidimensional industry classification systems by Shankling and Ryans, Felstenstein and Bar-el, Keeble, but as Carrol et al. (2000) showed, the classification indicators were questionable, hard to measure and construe. That is why the main impulse in industry classification was made by Hatzichronoglou (1997), who developed a system, where manufacturing industries were classified to different levels of technologies used. The indicators of direct and indirect R\&D intensities were used to classify manufacturing industries across 11 OECD countries.

The main idea of using the indicator of indirect R\&D was to show that technologies may not only be created in an industry (case of direct R\&D intensity), they may also be "embodied in intermediates and capital goods purchased on the domestic market or imported. Technology moves from one industry (and one country) to another when the industry performing R\&D sells its products embodying that R\&D to other industries which use them as manufacturing inputs" (Hatzichronoglou, 1997). Employing both direct and indirect R\&D intensities in the industries classification system, the system combines in one both the creators of new technologies and the users of these new technologies (embodied in intermediate products) and classifies manufacturing industries to four groups: high-tech, medium high-tech, medium lowtech and low-tech industries (Table 1).

The system proposed by Hatzichronoglou (1997) is used in the official OECD manufacturing industry classification. The OECD classification, however, is based only on the indicator of direct R\&D intensity because of the lack of data (OECD, 2007). In the OECD classification system industries are allocated as follows: industries that spend more than $5 \%$ of sales on R\&D are classified as high-tech; those that spend between 3-5\%, as medium-high-tech; those that spend between 0.9-3\%, as medium-low-tech; and those that spend less than 0.9\%, as low-tech (Hirsch-Kreinsen et al., 2006).

It is worth to notify that OECD manufacturing industry classification to four groups is related to the whole OECD area, but not to individual countries, where industries' allocation to technological levels may be different. The widespread OECD industry classification system is convenient to use: it allows comparing of technological advancement and situation across countries, as the data of R\&D expenses is treated in the same way. On the other hand, this ready-to-use classification system does not reflect exact situation in every economy's innovation and technological efforts in different manufacturing industries.

Table1. Industry classification to levels of technology

\begin{tabular}{|l|l|l|l|l|c|}
\hline $\begin{array}{c}\text { Level of } \\
\text { technology }\end{array}$ & \multicolumn{1}{|c|}{ Industries } & $\begin{array}{c}\text { Dir+indir R\&D/ } \\
\text { production }\end{array}$ & $\begin{array}{c}\text { Level of } \\
\text { technology }\end{array}$ & Industries & $\begin{array}{c}\text { R\&D } \\
\text { share }\end{array}$ \\
\hline High- & Aircraft and spacecraft & $\mathbf{> 7 \%}$ & Medium- & Electrical machinery and & $\mathbf{2 . 5 - 7 \%}$ \\
\hline
\end{tabular}




\begin{tabular}{|l|l|l|l|l|l|}
\hline $\begin{array}{l}\text { technology } \\
\text { industries }\end{array}$ & $\begin{array}{l}\text { Computers, office } \\
\text { machinery } \\
\text { Pharmaceuticals } \\
\text { Radio, TV and } \\
\text { communications } \\
\text { equipment }\end{array}$ & $\begin{array}{l}\text { high- } \\
\text { technology } \\
\text { industries }\end{array}$ & $\begin{array}{l}\text { apparatus. } \\
\text { Motor vehicles, trailers } \\
\text { and semi-trailers } \\
\text { Chemicals, excluding } \\
\text { pharmaceuticals } \\
\text { Other transport } \\
\text { equipment } \\
\text { Non-electrical machinery }\end{array}$ & Wood and furniture \\
$\begin{array}{l}\text { Medium-low- } \\
\text { technology } \\
\text { industries }\end{array}$ & $\begin{array}{l}\text { Shipbuilding } \\
\text { Rubber and plastics } \\
\text { products } \\
\text { Petroleum refining, } \\
\text { nuclear fuel } \\
\text { Other non-metallic } \\
\text { mineral products } \\
\text { Metals and metal } \\
\text { products } \\
\text { Other manufacturing }\end{array}$ & $\mathbf{1 - 2 . 5 \%}$ & $\begin{array}{l}\text { Low- printing } \\
\text { technology- } \\
\text { industries } \\
\text { Food products, beverages } \\
\text { and tobacco } \\
\text { Textiles and clothing }\end{array}$ & $<1 \%$ \\
& & & & & \\
\end{tabular}

Source: adapted by the authors with reference to Hatzichronoglou (1997).

In the above mentioned classification systems the main classification criteria is technological intensity expressed by R\&D share to turnover. However, this measure of innovations does not convey the full spectrum of innovating activities that may change the view of so deemed the most non-innovative, non-knowledge intensive sector of low-tech. Moreover, the $R \& D$ as a measure of innovations is more addressed to only high-tech sector, which, as stated by Zarzewska-Bielawska (2012), declare high levels of R\&D expenditures, innovation rates and therefore is known as knowledge intensive sector. However, some studies that address namely low-tech innovations issue show that low-tech companies may evidence other innovation resources than direct R\&D expenses; these are inner resources and capacities to make innovations, employing which low-tech companies demonstrated high growth rate and competitiveness (Hirsch-Kreinsen et al., 2006; Smith, 2000).

Robertson and Patel (2006) explain how low-tech companies may even become innovation "pushers" in high-tech sector: being the customers of high-tech products, low-tech companies address high-tech for new and innovative products, and therefore such reciprocal relationships between the two sectors enhance the level of overall resources devoted to R\&D.

A new approach to measuring innovativeness and an alternative system of technology indicators was presented by Laestadius et al. (2006). The authors suggest five indicators, each having several variables; these indicators are:

a) R\&D intensity;

a) Design intensity

a) Technological intensity;

a) Skill intensity (human capital orientation);

a) Innovation intensity.

In addition Laestadius et al. (2006) add one more indicator to their classification system - organizational skills/creativity, which may be defined as organizational capabilities/innovations/competencies that companies develop and use successfully to their growth. On the other hand, lack of genuine data may become an obstacle to using this additional indicator. The authors themselves point out this indicator can be incorporated as a variable in innovation intensity indicator.

The classification system proposed by Laestadius et al. (2006) complements OECD classification system and classifies industries so, that variety of innovativeness through the industries (as defined by OECD) is captured. Innovativeness is clearly related to higher competitiveness of companies. The more companies innovate, the more they may feel stronger and exclusive in the global market and seek for competitive advantage. That means, innovations have to be commercialized, or to say so, be successful. We suggest using an additional indicator of successful innovation activity - orientation to export, expressed by export share to turnover. Such indicator is very important for small and open economy countries, like Lithuania is. Even for medium scale (not to talk about larger scale) innovating companies, producing in a country with a squeezed home market, the only way to use their technological or other kind of innovations and run a successful business is to be competitive in the international marketplace. In small open economy countries the 
case, when companies start their export activities first and only later turn to home market for additional sales, is also true. Therefore we think that the indicator of orientation to export is worth when analysing manufacturing industries in small open economy countries.

\section{Method}

When making the comparative analysis across manufacturing industry sectors, we treat industrial sectors as they are distinguished by OECD, but to represent the full view we employ five indicators of Laestadius et al. (2006). Also the additional indicator of orientation to export is added. For each of the indicators we select variables that we think fits the best. Also availability of data plays important role.

In the analysis we use the latest available statistical data from Lithuanian Department of Statistics (Statistics Lithuania) of the year 2010 and 2011. Though for some variables (like turnover or the like) we may find the data for the year 2012, but for the sake of comparability data of 2011 was chosen were possible, otherwise we used data of the year 2010. Data about patents and designs was retrieved from the State Patent Bureau of the Republic of Lithuania data basis.

In some Lithuanian industries only several companies operate and statistical data is missing, hence we also use available data from Odin BvD database of the corresponding year to fill in data gaps to have as much complete data, as possible.

\section{Results and discussion}

\subsection{R\&D intensity}

The most common indicator to describe technological level of an industry is R\&D intensity, expressed by share of each sector's mean R\&D expenditures in turnover. As it can be seen in Figure 1 by the column chart, Lithuanian manufacturing industry in total demonstrates very modest 0.19 per cent of R\&D expenditures share in turnover. The proportions of R\&D expenditures correspond to OECD classification system in a sense that high-tech sector allocates the largest per cent of the turnover to R\&D and correspondingly the lower technology sector is the less R\&D expenditures it has. Low-tech sector spends just 0.06 per cent of turnover to R\&D, however it makes the largest part (10.7 per cent) of turnover in total economy comparing with other manufacturing sectors, as it is shown in Figure 1 by the line chart.

The high-tech sector, though being the leader in R\&D expenditures, makes very small percentage of 0.7 per cent in total economy turnover. That means low-tech sector being the largest manufacturing industry sector makes 17.6 per cent of total R\&D in manufacturing industries (Figure 2). When analysing each sector's R\&D share in manufacturing industry total $R \& D$ expenditures, medium-high-tech sector almost reaches high-tech's percentage of $R \& D$ share in manufacturing industry R\&D expenditures, and medium-low-tech sector demonstrates the lowest share of only 10.7 per cent.

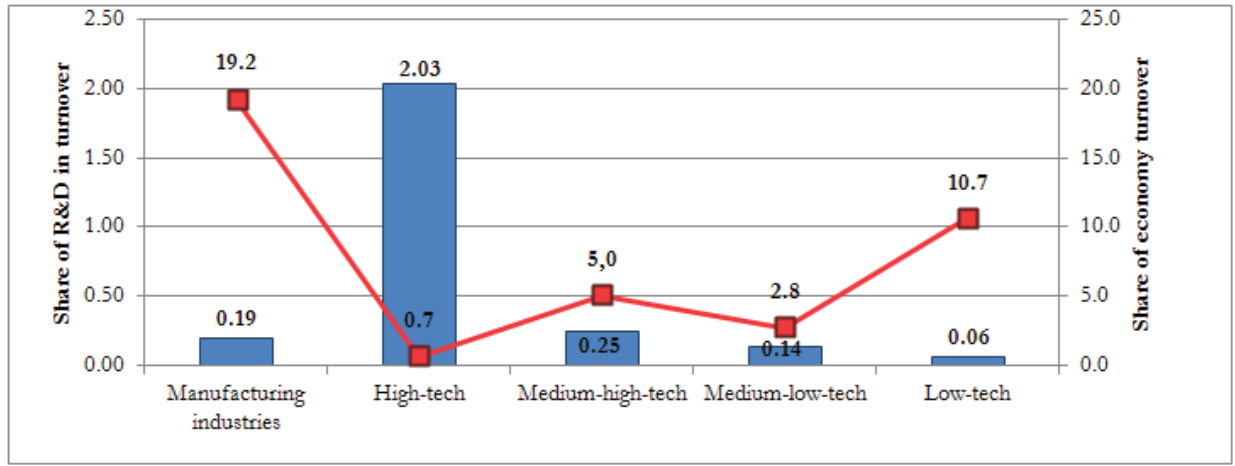

Figure 1. Share of R\&D in turnover and share of total economy turnover of manufacturing industry and its separate sectors in 2011, per cent. 


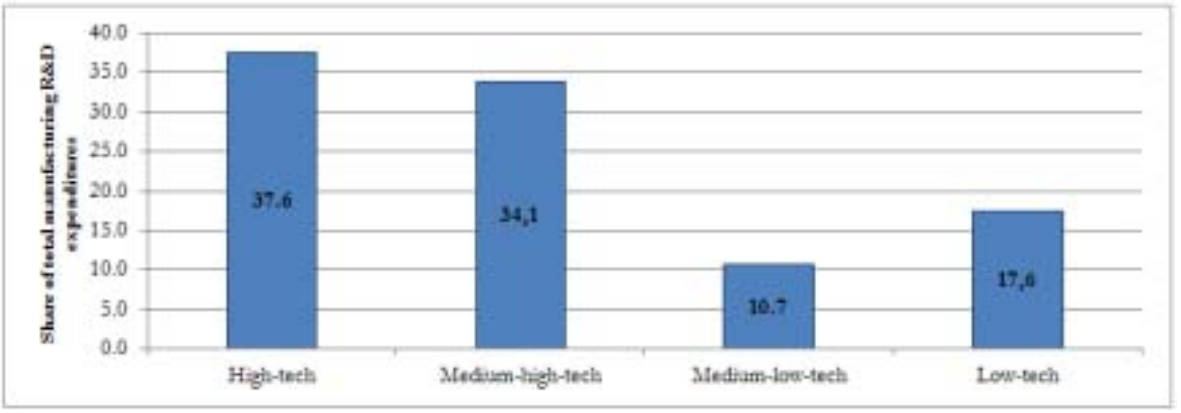

Figure 2. Share of each sector's R\&D expenditures in manufacturing industry R\&D expenditures in 2011, per cent.

\subsection{Design intensity}

This indicator we explain by using share of companies in each sector that registered designs in manufacturing industry and share of number of companies in manufacturing industry (Figure 3). Low-tech sector, having the largest number of companies in manufacturing industry, evidences the largest proportion of registered designs comparing with other sectors in 2011. Interestingly, high-tech sector did not register any designs in 2011.

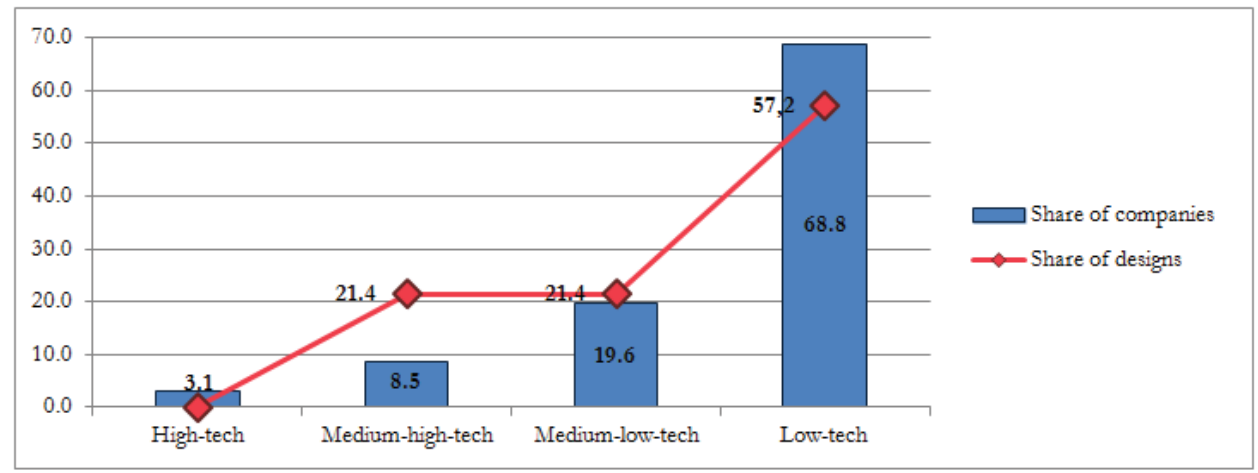

Figure 3. Share of designs and companies in each sector of manufacturing industry in 2011, per cent

\subsection{Technological intensity}

We use variable of share of each sector's expenditures on machinery and equipment in turnover (i.e. of companies that registered technological innovations) to measure the indicator of technological intensity and compare it with each sector's share of employment in total economy's employment. As Figure 4 shows by column chart, medium-low-tech sector is the larger investor in new equipment and machinery, though the sector employment (line chart) is only 3.8 per cent in the economy. The largest share of employment in the manufacturing industry goes to low-tech sector, but it spends only 0.5 per cent of its turnover on investment in new equipment and machinery. That may be explained by the fact that low-tech industry leans on less technologically advanced machinery and equipment and low-skilled work force employment. 


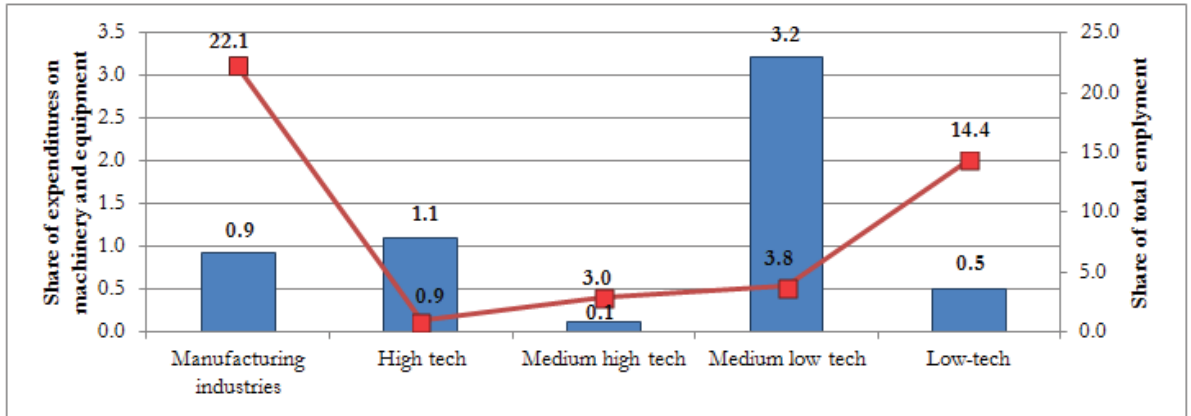

Figure 4. Share of expenditures on machinery and equipment in turnover and share or total employment in 2010, per cent.

Structure of different types of expenditures in each sector is useful to see the full view of innovation expenditures of companies that registered technological innovations (Figure 5). Proportions of expenditures of different types in total manufacturing industry correspond to the situation in the economy, i.e. the largest part of expenditures goes to acquisition of machinery and equipment. Very similar situation is in low-tech sector, which divert most of expenditures to the machinery and equipment, though the largest investment to it is made by medium-low-tech sector. High-tech sector makes considerably larger investment in acquiring of external knowledge comparing with other sectors, manufacturing industry and total economy; it also allocates large part on expenditures to training. The largest proportion of expenditures to training, however, is made by medium-high-tech sector.

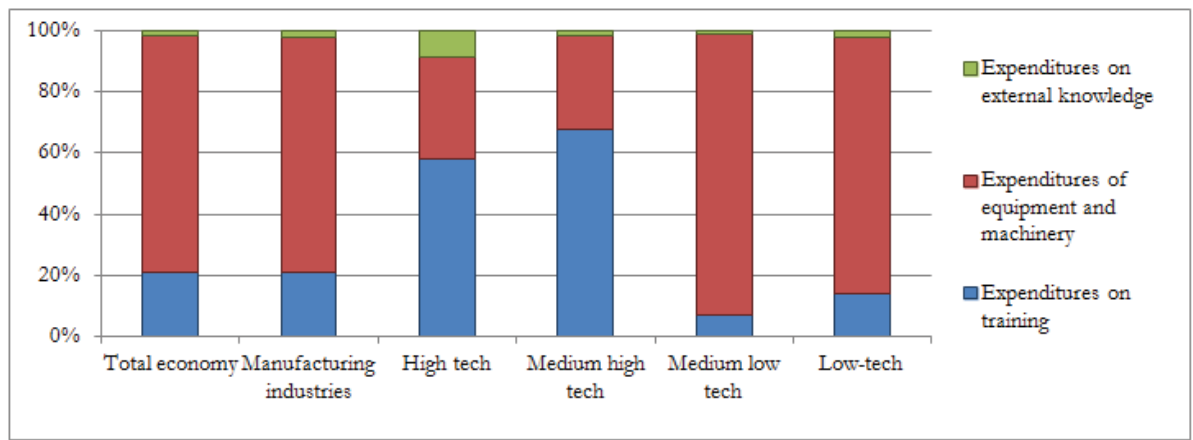

Figure 5. Innovation expenditures of companies that registered technological innovations in 2010 by type of expenditure, per cent.

\subsection{Skill intensity}

This indicator shows how much effort is allocated to high skilled employment in each sector. Therefore we use share of R\&D employment in total employment variable to demonstrate these efforts in each sector and in manufacturing industry in total. Figure 6 shows by column chart that 3.28 per cent of employees in high-tech sector are working in R\&D department.

This explains low level of R\&D employees in manufacturing industry, as high-tech sector employs only 0.94 per cent of total employment (shown by line chart). Low-tech sector has scarce 0.13 per cent of R\&D employment in the sector's total employment, however we should remember that the sector is large and therefore R\&D employment in absolute numbers is respectively considerable. Also medium-low tech sector employs small percentage of R\&D employees, and total employment in this sector is not extensive, as well. 


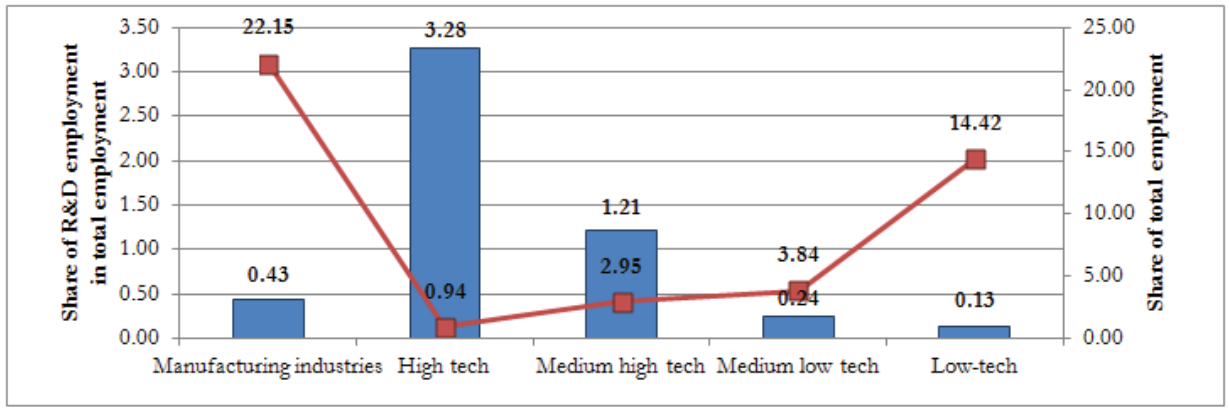

Figure 6. Share of R\&D employment in total employment and share of total employment in each sector in 2011, per cent.

\subsection{Innovation intensity}

Several variables are used to measure innovation intensity, these include: share of registered patent in manufacturing industry; share of innovative companies' turnover in sector turnover; share of innovative companies' employment in sector employment (Figure 7). It is impressive to notice the low-tech sector has the same share of registered patents as high-tech and medium-high-tech sectors, though low-tech's percentage of both innovative companies' turnover and employment in innovative companies is the smallest through all the sectors of Lithuanian manufacturing industry. Again, it's worth noticing that neither the share of innovative companies' turnover, nor their employment have a remarkable distance from the corresponding shares in other sectors.

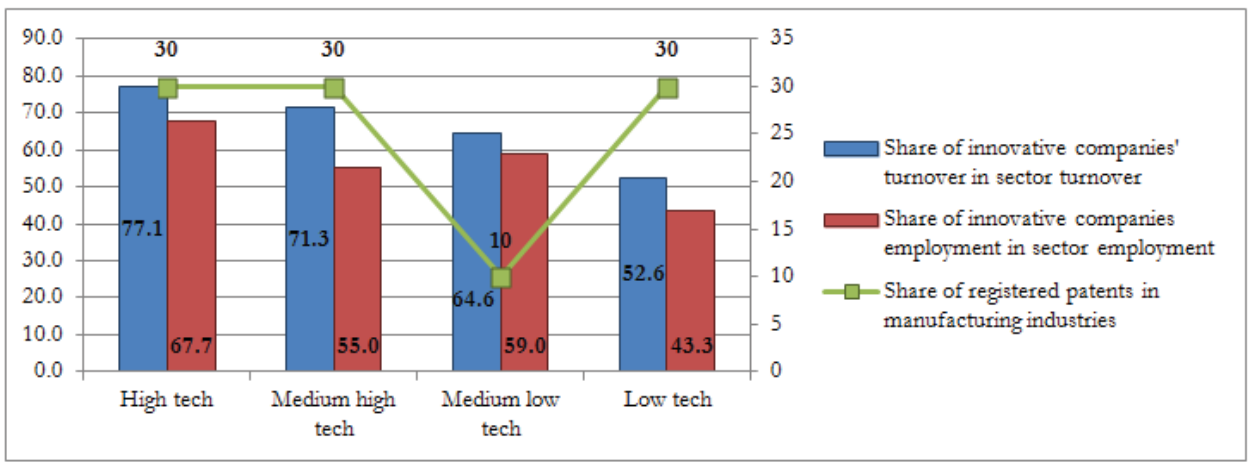

Figure 7. Share of registered patents, innovative companies' turnover and employment in the corresponding sector in 2010, per cent.

\subsection{Orientation to export}

Indicator of orientation to export shows how intensively the sector is involved in international market and export activities. Share of export in sector's turnover demonstrates that Lithuanian manufacturing industry is dependent on export, as total manufacturing industry export exceeds 67 per cent, as shows Figure 8. In fact, all sectors generate more than half of turnover from exporting. Especially high export share is in high-tech industry, as Lithuania is a large-scale player in world laser market, but the sector itself being a small part of manufacturing industry, its export share makes only little above 4 per cent in export of manufacturing industry (not shown in the chart). Meanwhile low-tech sector exports 58.9 per cent, but being the largest sector in manufacturing industry ( 55.4 per cent), makes almost half of manufacturing industry export. 


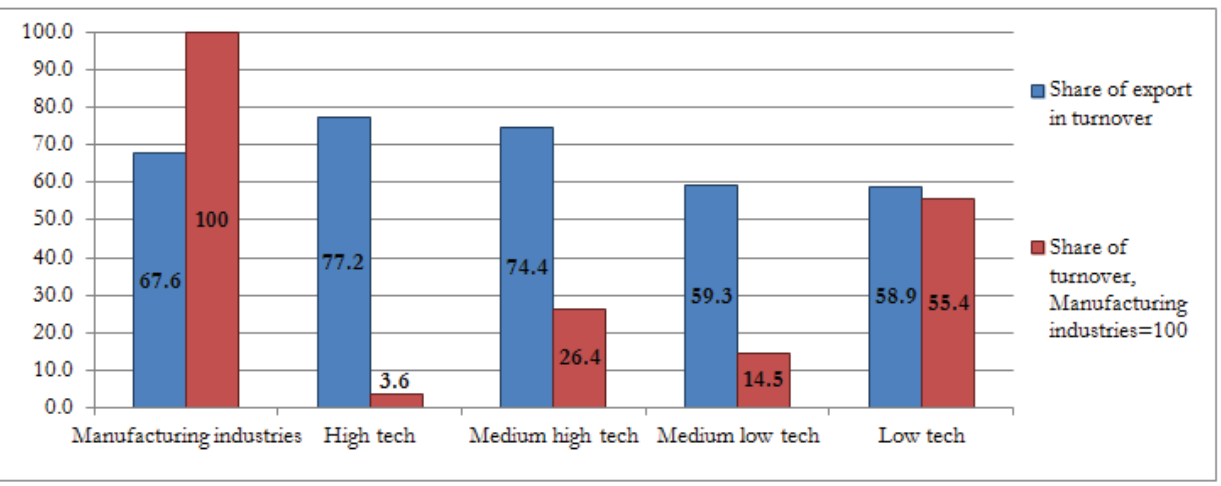

Figure 8. Share of export in turnover and share of turnover in manufacturing industries in 2011, per cent.

\section{Conclusions}

The paper aimed to show low-tech sector's significance and role in Lithuanian economy, also we wanted to show that not only high-tech, but also low-tech sector may and important and help to reach strategic economic objectives in the country. In most of the researches in industrial development the main stress is made on high-tech sector which is deemed to be the main driving force to economy growth and prosperity. However, later studies revealed that low-tech is a very important and underestimated part of even advanced economies, that's why low-tech sector is worth of attention not only for researchers, but for policy makers, as well.

Our research showed that low-tech is very important to Lithuanian economy: it is the largest sector in manufacturing industry, employs significant share of total employment, is extensive exporter, registers significant part of patents and is even a leader in design intensity. However, scarce R\&D employment and investment in new equipment and machinery in low-tech may lead to reduced international competitiveness. On the other hands, extensive designing means that low-tech companies seek to gain competitiveness through design, not technological innovations.

It is worth noticing that all sectors of Lithuanian manufacturing industry demonstrate low level of R\&D expenditures - in fact, even high-tech sector does not reach the cut-off point for high-tech as described by OECD. This may be due to the fact that companies modestly register their R\&D expenditures to gain tax incentives because of bureaucratic obstacles. Despite that fact, low-tech sector is not the last among other sectors in R\&D expenditures share. Therefore we may conclude that high-tech sector, being very small one, should not be seen as the only salvation for the economy by policy makers. On the contrary, low-tech sector could show better results not only in terms of exporting and employment, but also in $R \& D$ area, if bureaucratic requirements would be more reasonable to the companies.

\section{Funding}

The authors acknowledge the funding of The Research Council of Lithuania to make the research by project No. IEP01/2012.

\section{References}

Carrol, P., Pol, E., \& Robertson, P.L. (2000). Classification of Industries by Level of Technology: an Appraisal and some Implications. Prometheus, Vol. 18, No. 4, DOI: 10.1080/08109020020008523.

European Commission (2010). Europe 2020. [Online] Available: http://ec.europa.eu/economy_finance/structural_reforms/ europe_2020/index_en.htm

Eurostat (2013). News Release Euro Indicators. [Online] Available: http://europa.eu/rapid/press-release_STAT-13-31_en.htm

Hatzichronoglou, T. (1997). Revision of the High-Technology Sector and Product Classification. OECDScience, Technology and Industry Working Papers,1997/02, OECD Publishing. [Online] Available: http://dx.doi.org/10.1787/134337307632

Hirsch-Kreinsen, H. (2005). Low-Tech Industries" Innovativeness and Development Perspectives. In: G.Bender, D.Jacobson, \& P.L.Robertson (Eds.), Non-Research-Intensive Industries in the Knowledge Economy. Perspectives on Economic Political and 
Social Integration, Special Issue1. Lublin: Catholic University.

Hirsch-Kreinsen, H., Jacobson, D., Robertson, P.L. (2006). 'Low-tech' Industries: Innovativeness and Development Perspectives - A Summary of a European Research Project. Prometheus, Vol. 24, No.1, DOI:10.1080/08109020600563762.

Laestadius, S., Pedersen, T.E., Sandven, T. (2006). Towards a New Understanding of Innovativeness - and of Innovation Based Indicators. In: G.Bender, D.Jacobson, \& P.L.Robertson (Eds.), Non-Research-Intensive Industries in the Knowledge Economy. Perspectives on Economic Political and Social Integration, Special Issue1. Lublin: Catholic University.

Robertson, P.L., \& Patel, P.R. (2006). New wine in old bottles. Technological diffusion in developed economies. In: Bender, G., Jacobson, d., Robertson, P.L. (eds.), Non-Research-Intensive Industries in the Knowledge Economy. Perspectives on Economic Political and Social Integration, Special Issue1. Lublin: Catholic University.

Smith, K. (2000). What is the "knowledge economy"? Kwoldege-intensive indutries and distributed knowledge bases. Oslo: STEP Group.

Zarzewska-Bielawska, A. (2012). The strategic dilemas of innovative enterprises: proposals for high-technology sectors. 